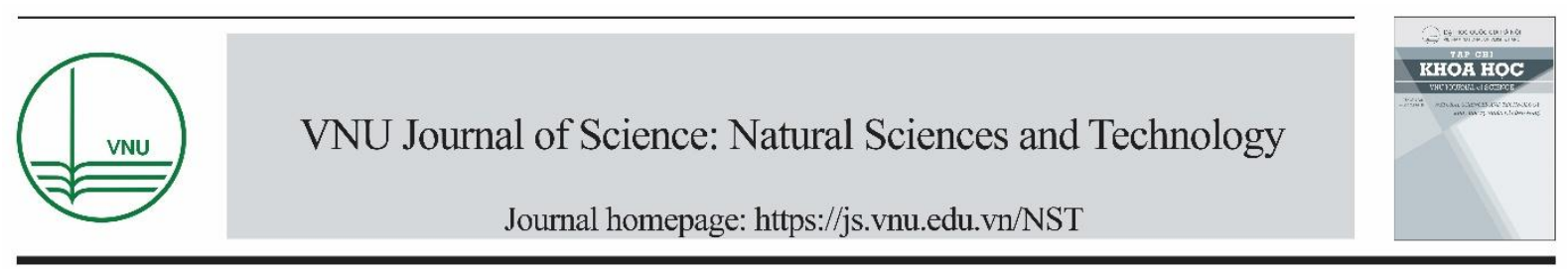

Original Article

\title{
Novel Alterations of Some Mitochondrial tRNA Genes in Vietnamese Colorectal Cancer Patients
}

\author{
Pham Thi Bich ${ }^{1}$, Nguyen Thi Van ${ }^{1}$, Ta Van To ${ }^{2}$, Trinh Hong Thai ${ }^{1, *}$ \\ ${ }^{1}$ Faculty of Biology, VNU University of Science, 334 Nguyen Trai, Thanh Xuan, Hanoi, Vietnam \\ ${ }^{2}$ Department of Anatomical Pathology - Cytopatology, Vietnam National Cancer Hospital, \\ 30 Саu Виоu, Tan Trieu, Thanh Tri, Hanoi, Vietnam \\ Received 14 January 2019 \\ Revised 13 March 2019; Accepted 15 March 2019
}

\begin{abstract}
Some mutations of mt-DNA which encode tRNA (mt-tRNA) were previously reported to be associated with clinical manifestations of neuromuscular disorders syndrome. In addition, alterations of the mitochondrial genome have been suggested to contribute to mitochondrial dysfunction and tumorigenesis. Alterations in some mt-tRNA genes have also been identified in breast cancer, lung cancer and colorectal cancer. However, so far, there has not been any report on mt-tRNA gene alteration in the Vietnamese colorectal cancer patients. This study analyzes the alterations of some mt-tRNA genes in a group of Vietnamese colorectal cancer patients and predicts the influence of the alterations on the secondary structure of tRNA based on bioinformatic tools. PCR-RFLP and DNA sequencing methods were used to screen alterations; the secondary structure of tRNA was predicted in silico by using a tool of the Vienna RNA Websuite. The study results show that both A12309G and A12310G of tRNA ${ }^{\text {Leu }}$ were identified together in two out of 98 patients, and both T12150G and C12154G of tRNA ${ }^{\text {His }}$ were identified in one out of 19 patients. ${ }^{1}$ All these alterations are heteroplasmic and have not been reported in cancer patients so far. In particular, the $\mathrm{C} 12154 \mathrm{G}$ alteration in the DHR loop led to changes in the secondary structure of tRNA ${ }^{\text {His }}$ and could affect the function of this tRNA molecule.
\end{abstract}

Keywords: mt-tRNA, Vietnamese colorectal cancer, PCR-RFLP, DNA sequencing.

${ }^{*}$ Corresponding author.

Email address: thaith@vnu.edu.vn

https://doi.org/10.25073/2588-1140/vnunst.4856 


\title{
Biến đổi mới của một số gen ty thể mã hóa cho tRNA ở bệnh nhân ung thư đại trực tràng người Việt Nam
}

\author{
Phạm Thị Bích ${ }^{1}$, Nguyễn Thị Vân ${ }^{1}$, Tạ Văn Tờ르 Trịnh Hồng Thái ${ }^{1, *}$ \\ ${ }^{1}$ Khoa Sinh họ, Truòng Đại học Khoa học Tư nhiên, ĐHQGHN, \\ 334 Nguyễn Trãi, Thanh Xuân, Hà Nội, Việt Nam \\ ${ }^{2}$ Khoa Giải phẫu bệnh, Tế bào, Bệnh viện K, 30 Cầu Buou, Tân Triều, Thanh Trì, Hà Nội, Việt Nam \\ Nhận ngày 14 tháng 01 năm 2019 \\ Chỉnh sửa ngày 13 tháng 03 năm 2019; Chấp nhận đăng ngày 15 tháng 03 năm 2019
}

\begin{abstract}
Tóm tắt: Một số đột biến gen trên ADN ty thể mã hóa cho phân tử tRNA (mitochondrial tRNA: mt-tRNA) đã được xác định có liên quan đến biểu hiện lâm sàng và thường gây ra các hội chứng liên quan đến các bệnh về cơ và thần kinh. Bên cạnh đó, những thay đổi trong hệ gen ty thể dẫn đến rối loạn chức năng ty thể từ lâu đã được giả thiết góp phần vào sự phát sinh khối u. Ở ung thư vú, ung thư phổi, ung thư đại trực tràng (UTĐTT), biến đổi của gen mt-tRNA cũng đã được xác định, tuy nhiên, chúng tôi chưa tìm thấy nghiên cứu nào trên đối tượng UTĐTT người Việt Nam. Vì vậy, trong nghiên cứu này, chúng tôi đã tiến hành sàng lọc biến đổi của một số gen mt-tRNA ở một nhóm bệnh nhân UTĐTT người Việt Nam và dự đoán ảnh hưởng của một số vị trí biến đổi tìm được đến cấu trúc bậc hai của tRNA. Sử dụng kỹ thuật PCR-RFLP, giải trình tự ADN để sàng lọc biến đổi và phương pháp mô hình hóa phân tử RNA để dự đoán sự thay đổi cấu trúc bậc hai của chúng. Kết quả chúng tôi đã xác định thấy 2 trên 98 bệnh nhân có đồng thời hai biến đổi A12309G và $\mathrm{A} 12310 \mathrm{G}$ thuộc tRNA ${ }^{\mathrm{Leu}}, 1$ trên 19 bệnh nhân có đồng thời hai biển đổi T12150G và C12154G thuộc tRNA ${ }^{\text {His }}$. Các biến đổi nêu trên đều ở dạng dị tế bào chất và đều chưa được công bố trên đối tượng bệnh nhân ung thư. Đặc biệt, biến đổi C12154G thuộc vùng DHU của tRNA ${ }^{\text {His }}$ được dự đoán làm thay đổi cấu trúc bậc hai của phân tử và có thể ảnh hưởng đến chức năng của phân tử tRNA.
\end{abstract}

Tù khóa: Biến đổi của gen mt-tRNA, UTĐTT người Việt Nam, PCR-RFLP, giải trình tự ADN.

\footnotetext{
*Tác giả liên hệ.

Địa chỉ email: thaith@vnu.edu.vn

https://doi.org/10.25073/2588-1140/vnunst.4856
} 


\section{Mở đầu}

Hiện nay, tỷ lệ mắc mới và tử vong do UTĐTT vẫn đang ở mức cao trên thế giới và ở Việt Nam, điều đó cho thấy đây là căn bệnh nguy hiểm và vẫn đang là gánh nặng toàn cầu [1]. Trong các yếu tố liên quan đến ung thư thì rối loạn $\mathrm{ADN}$ ty thể được xem là một yếu tố nguy cơ [2]. Trong đó, mối liên quan giữa biến đổi của các gen tRNA với ung thư ngày càng được quan tâm. Ở ung thư gan, một số dạng biến đổi đã được xác định bao gồm biến đổi T1659C thuộc gen tRNA ${ }^{\mathrm{Val}}$, G5650A thuộc gen tRNA $^{\text {Ala }}$, T10463C thuộc gen tRNA ${ }^{\text {Arg }}$, A14679G thuộc gen tRNA Glu và C15975T thuộc gen tRNA ${ }^{\text {Pro }}$ [3]; biến đổi A12308G thuộc gen tRNA ${ }^{\text {Leu }}$ được tìm thấy ở UTĐTT [4] và bệnh ung thư miệng [5]. Ngoài ra, biến đổi A7460G thuộc gen tRNA ${ }^{\text {Ser }}$, G5563A thuộc gen tRNA $^{\text {Trp }}$ và $A 12172 \mathrm{G}$ thuộc gen tRNA ${ }^{\text {His }}$ được xác định ở ung thư phổi [6]. Tuy nhiên, việc sàng lọc đột biến trên mt-tRAN vẫn chưa được thực hiện ở UTĐTT người Việt Nam. Vì vậy, nghiên cứu biến đổi của tRNA ở UTĐTT và ảnh hưởng của một số biến đổi tìm được đến cấu trúc hoặc chức năng của phân tử tRNA là cần thiết.

Trong nghiên cứu này, chúng tôi đã sử dụng phương pháp PCR-RFLP, giải trình tự để sàng lọc biến đổi của các gen mt-tRNA và dùng phương pháp mô hình hóa phân tử RNA in silico [7] để mô hình hóa phân tử RNA và dự đoán sự thay đổi cấu trúc của RNA tại một số vị trí biến đổi xác định được.

\section{Nguyên liệu và phương pháp}

\subsection{Nguyên liệu}

Mẫu nghiên cứu là mẫu mô của bệnh nhân UTĐTT được lấy tại vị trí khối u và vị trí lân cận khối u (cách khối u tối thiểu $5 \mathrm{~cm}$, diện cắt được xác định không còn tế bào ung thư). Mẫu nghiên cứu cùng với các thông tin của bệnh nhân như độ tuổi, giới tính, vị trí, kích thước $\mathrm{u}$, độ biệt hóa và giai đoạn bệnh do Khoa Tế bào Giải phẫu bệnh, bệnh viện $\mathrm{K}$ cung cấp. Trong nghiên cứu này, chúng tôi đã tập trung sàng lọc đột biến $\mathrm{A} 3243 \mathrm{G}$ trên 30 cặp mẫu, đột biến G12300A trên 68 cặp mẫu, đột biến A12308G trên 98 cặp mẫu và giải trình tự $\mathrm{ADN}$ để sàng lọc các biến đổi khác của các gen mã hóa cho một số tRNA trên19 mẫu.

\subsection{Phuoong pháp}

Tách chiết $A D N$ tổng số: $\mathrm{ADN}$ tổng số từ mẫu mô của bệnh nhân UTĐTT được tách chiết bằng kit QIAamp DNA Mini Kit (QIAGEN, Đức). Kit tách chiết này đảm bảo việc tách được cả $\mathrm{ADN}$ ty thể. Các bước được tiến hành theo quy trình của nhà sản xuất. $\mathrm{ADN}$ sau khi tách chiết được xác định nồng độ và độ sạch bằng máy quang phổ Nano drop $2000 \mathrm{c}$ (Thermo, Mỹ) và bảo quản ở $-20^{\circ} \mathrm{C}$.

Phuoong pháp PCR-RFLP: Các đoạn gen mt-tRNA chứa các vị trí 3243, 12300, 12308 được khuếch đại bằng phản ứng $\mathrm{PCR}$ với các cặp mồi đặc hiệu được thiết kế bằng phần mềm Primer-BLAST trong NCBI. Trình tự các cặp mồi sử dụng cho nghiên cứu được trình bày trong Bảng 1.

Bảng 1. Các cặp mồi được dùng trong phản ứng PCR-RFLP

\begin{tabular}{|c|c|c|c|c|}
\hline $\begin{array}{l}\text { Tên } \\
\text { mồi }\end{array}$ & & Trình tự mồi & $\begin{array}{l}\text { Kích thước sản } \\
\text { phẩm PCR (bp) }\end{array}$ & Mục đích \\
\hline \multirow{2}{*}{3243} & $\mathrm{~F}$ & 5'-CTGTACGAAAGGACAAGAGA-3' & & \multirow{4}{*}{$\begin{array}{l}\text { Nhân đoạn ADN } \\
\text { chứa vị trí } 3243 \\
\text { Nhân đoạn } \mathrm{ADN} \\
\text { chứa vị trí } 12300 \text { và } \\
12308\end{array}$} \\
\hline & $\mathrm{R}$ & 5'ACAATGAGGAGTAGGAGGTT-3' & 218 & \\
\hline \multirow{2}{*}{12300} & $\mathrm{~F}$ & 5'-CTGACAACAGAGGCTTACGA-3' & \multirow[b]{2}{*}{346} & \\
\hline & $\mathrm{R}$ & 5'-AACTTCTTGGTCTAGGCACAT-3' & & \\
\hline \multirow{2}{*}{7375} & $\mathrm{~F}$ & 5'-ATGAGGAATAGTGTAAGGAGTA-3' & \multirow{3}{*}{1059} & \multirow{4}{*}{$\begin{array}{l}\text { Nhân đoạn } \mathrm{ADN} \\
\text { dùng cho giải trình } \\
\text { tự trực tiếp }\end{array}$} \\
\hline & $\mathrm{R}$ & 5'-ACCTGGAGTGACTATATGGAT-3' & & \\
\hline \multirow{2}{*}{11718} & $\mathrm{~F}$ & 5'-AACTTCTTGGTCTAGGCACAT-3' & & \\
\hline & $\mathrm{R}$ & 5'-GGCTTACATCCTCATTACTATTCT-3' & 801 & \\
\hline
\end{tabular}


Phản ứng PCR gồm các thành phần: $6,25 \mu 1$ OneTaq Hot Start 2x Master Mix (Neb, Mỹ); $0,2 \mu \mathrm{M}$ mồi gồm mồi xuôi và mồi ngược, 12,5 31 ng ADN khuôn, sau đó bổ sung $\mathrm{H}_{2} \mathrm{O}$ đến 12,5 $\mu \mathrm{l}$. Chu trình nhiệt của phản ứng PCR gồm biến tính ở $94^{\circ} \mathrm{C}$ trong 30 giây, gắn mồi ở $54^{\circ} \mathrm{C}$ trong 30 giây và kéo dài mạch ở $68^{\circ} \mathrm{C}$ trong 30 giây, thực hiện phản ứng PCR với 35 chu kỳ. Dựa trên trình tự của sản phẩm PCR được nhân bản theo các cặp mồi thiết kế, chúng tôi đã lựa chọn được các enzyme giới hạn phù hợp để phát hiện biến đổi bằng RFLP, trình tự nhận biết của các enzyme dùng trong nghiên cứu được trình bày ở Bảng 2 :

Bảng 2. Các enzyme được sử dụng trong nghiên cứu

\begin{tabular}{|c|c|c|c|c|}
\hline \multirow{2}{*}{ Loại đột biến } & \multirow{2}{*}{$\begin{array}{l}\text { Loại } \\
\text { enzyme }\end{array}$} & \multirow{2}{*}{ Trình tự nhận biết } & \multicolumn{2}{|c|}{ Kích thước sản phẩm cắt (bp) } \\
\hline & & & ADN không bị đột biến & ADN đột biến \\
\hline A3243G & HaeIII & 51 $C G \mid C R$ & $22,27,169$ & $22,27,72$ và 97 \\
\hline G12300A & & . & 128 và 218 & 346 \\
\hline A12308G/A12309G & ApoI & $\begin{array}{l}5^{\prime} \ldots \mathrm{R} \downarrow \text {.AATTY ...3' } \\
(\mathrm{R}: \mathrm{A} / \mathrm{G}) \quad(\mathrm{Y}: \mathrm{C} / \mathrm{T})\end{array}$ & 346 & 135 và 211 \\
\hline
\end{tabular}

Sản phẩm $\mathrm{PCR}$ và sản phẩm cắt bằng enzyme được điện di kiểm tra trên gel agarose 2\%, nhuộm ethidium bromide hoặc gen polyacrylamide nhuộm bạc. Quan sát và chụp ảnh bản gel bằng hệ thống máy $\mathrm{Gel}$ Doc $\mathrm{TM}$ XR (Biorad).

Giải trình tụ $A D N$ : Bên cạnh sử dụng phương pháp PCR-RFLP để xác định các đột biến quan tâm, chúng tôi còn sử dụng phương pháp giải trình tự $\mathrm{ADN}$ để sàng lọc các đột biến khác của các gen mt-tRNA. Hai cặp mồi ký hiệu là 7375 và 11718 (trình tự ở Bảng 1) nhân lên các đoạn $\mathrm{ADN}$ có kích thước lần lượt là 1059 bp và 801 bp chứa các gen mã hóa cho tRNA $^{\text {Ser }}$ có vị trí: 7446-7514, tRNA ${ }^{\text {Asp: }}$ 75187585 , tRNA $^{\text {Lys: }}$ 8295-8364 và tRNA ${ }^{\text {His: }}$ 1213812206, tRNA ${ }^{\text {Ser: }}$ 12207-12265, tRNA $^{\text {Leu: }}$ 12266- 12336. Đoạn $\mathrm{ADN}$ được giải trình tự thông qua công ty thương mại (công ty the 1 st BASE). Phần mềm Bioedit được dùng để phân tích kết quả giải trình tự. Kết quả giải trình tự được so sánh với trình tự $\mathrm{ADN}$ ty thể tham chiếu trên NCBI mã số NC_012920.1 bằng chương trình BLAST nucleotide trên NCBI [8] để xác định biến đổi.
Mô hình hóa phân tử RNA: Sử dụng chương trình RNAfold Server trong The Vienna RNA Websuite để dự đoán cấu trúc của RNA [7].

\section{Kết quả và thảo luận}

Sử dụng $\mathrm{ADN}$ tổng số được tách từ mẫu mô UTĐTT làm khuôn, các đoạn $\mathrm{ADN}$ chứa vị trí 3243, 12300, 12308 thuộc gen mt-tRNA ty thể đã được nhân lên bằng kỹ thuật PCR. Sau đó sản phẩm $\mathrm{PCR}$ được cắt bằng enzyme. Kết quả $\mathrm{PCR}$ được minh họa trong Hình $1 \mathrm{~A}$ và $1 \mathrm{~B}$. Hình $1 \mathrm{~A}$ và $1 \mathrm{~B}$ cho thấy, sản phẩm $\mathrm{PCR}$ từ các cặp mồi 3243 và 12300 đều cho một băng sáng, rõ nét, không có băng phụ với kích thước tương ứng theo tính toán lý thuyết khi thiết kế mồi, giếng đối chứng âm không có băng $\mathrm{ADN}$ chứng tỏ các cặp mồi được thiết kế là đặc hiệu, điều kiện phản ứng PCR là phù hợp. Ở các giếng số $2,4,6$ trong các hình $1 \mathrm{C}, 1 \mathrm{D}, 1 \mathrm{E}$ là sản phẩm $\mathrm{PCR}$ được cắt bằng enzyme $H a e I I I, A p o \mathrm{I}$ và HaeIII tương ứng.

Chúng tôi đã tiến hành sàng lọc đột biến A3243G trên gen mã hóa cho tRNA ${ }^{\text {Leu ơ } 30} 30$ cặp mẫu mô UTĐTT và đã không xác định thấy đột biến này ở các mẫu nghiên cứu (Hình1C). 




Hình 1. Ảnh điện di sản phẩm PCR và sản phẩm cắt bằng enzyme (gel agarose $2,0 \%$, nhuộm ethidium bromide, gel polyacylamid $8 \%$ nhuộm bạc).

Giếng M: Thang chuẩn ADN 50 bp. Hình $\mathrm{A}, \mathrm{B}$ : sản phẩm $\mathrm{PCR}$ chứa vị trí 3243 và 12300 , tương ứng. Hình $\mathrm{C}, \mathrm{D}$ và $\mathrm{E}$ : giếng $1,3,5$ : sản phẩm $\mathrm{PCR}$; giếng $2,4,6$ : sản phẩm cắt bằng enzyme của một số mẫu nghiên cứu. Hình $\mathrm{C}$ : sản phẩm PCR chứa vị trí 3243 và sản phẩm cắt bằng enzyme HaeIII. Hình $\mathrm{D}$, E: sản phẩm $\mathrm{PCR}$ chứa vị trí 12300,12308 và sản phẩm cắt bằng enzyme HaeIII, Apo $I$, tương ứng. Hình $\mathrm{F}$ : trình tự đoạn $\mathrm{ADN}$ và vị trí biến đồi $\mathrm{A} 12309 \mathrm{G}$ và $\mathrm{A} 12310 \mathrm{G}$.
Đột biến A3243G trên gen tRNA ${ }^{\text {Leu }}$ đã được phát hiện như là nguyên nhân của bệnh MELAS [9]. Cho đến nay, các nghiên cứu về đột biến A $3243 \mathrm{G}$ cũng thường tập trung vào một số bệnh cơ thần kinh, bệnh tiểu đường [10]. Đối với ung thư, đột biến $\mathrm{A} 3243 \mathrm{G}$ mới chỉ được báo cáo trên bệnh nhân UTĐTT với tần suất thấp và tồn tại ở dạng đồng tế bào chất [11]. Tuy nhiên, ở nhóm bệnh nhân UTĐTT người Việt Nam, chúng tôi lại không xác định thấy đột biến này

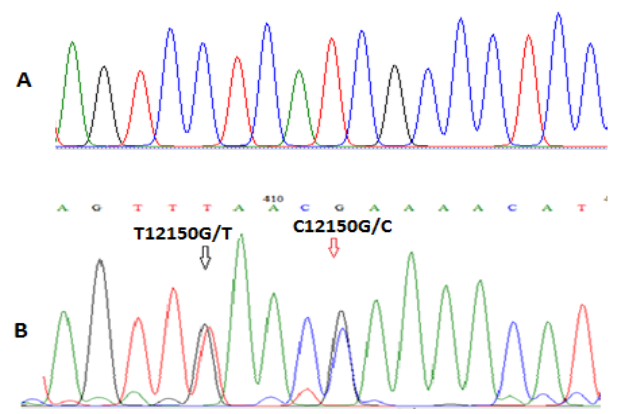

Hình 2. Trình tự đoạn $\mathrm{ADN}$ được nhân lên từ các cặp mồi 7375 (A) và cặp mồi 11718 (B).

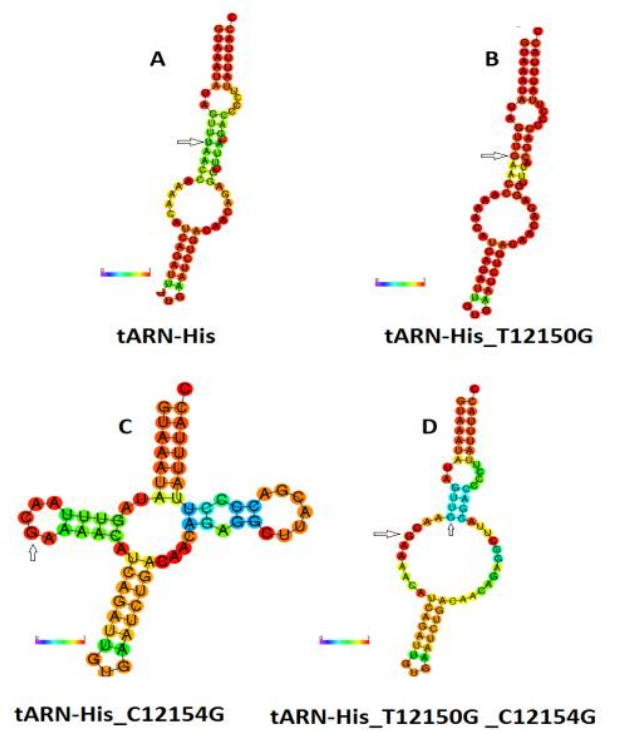

Hình 3. Mô hình dự đoán cấu trúc bậc hai của phân tử tRNA ${ }^{\text {His }}$ khi không có biến đổi $(\mathrm{A})$ và khi có các dạng biến đổi T12150G (B), C12154G (C) và khi có đồng thời cả hai biến đổi $\mathrm{T} 12150 \mathrm{G}$ và $\mathrm{C} 12154 \mathrm{G}$ (D) (mũi tên chỉ vị trí biến đổi). 
Như vậy, chúng tôi đã tiến hành sàng lọc biến đổi ở một số vị trí 3243, 12300, 12308 và 12309 thuộc gen ty thể mã hóa cho tRNA ${ }^{\text {Leu }}$ trên mẫu mô của một nhóm bệnh nhân UTĐTT. Tuy nhiên, tần suất của các biến đổi rất thấp. Vì vậy, chúng tôi đã thiết kế hai cặp mồi 7375 và 11718 để nhân các đoạn $\mathrm{ADN}$ dài 1059 bp và 801 bp tương ứng chứa các gen mã hóa cho tRNA $^{\text {Ser }}$ vị trí: 7446-7514, tRNA ${ }^{\text {Asp. }}$ 7518-7585, tRNA $^{\text {Lys: }}$ 8295-8364 và tRNA ${ }^{\text {His: }}$ 12138-12206, tRNA $^{\text {Ser: }}$ 12207-12265, tRNA $^{\text {Leu: }}$ 12266-12336, tinh sạch sản phẩm $\mathrm{PCR}$ và giải trình tự $\mathrm{ADN}$ để xác định các biến đổi.

Kết quả phân tích trình tự đoạn $\mathrm{ADN}$ được nhân lên bằng cặp mồi 7375 từ 19 mẫu mô ung thư, không có mẫu nào xuất hiện biến đổi ở vùng mã cho tRNA được nghiên cứu (Hình 2A). Trong khi đó, với đoạn ADN được nhân lên từ cặp mồi 11718 xác định thấy hai biến đổi đáng quan tâm là tại vị trí 12150 biến đổi $\mathrm{T}$ thành $\mathrm{G}$ và vị trí 12154 biến đổi $\mathrm{C}$ thành $\mathrm{G}$. Đặc biệt, biến đổi ở hai vị này đều ở dạng dị tế bào chất, cùng xuất hiện ở trong một mẫu nghiên cứu và đều thuộc gen tRNA ${ }^{\text {His }}$ (Hình $2 \mathrm{~B}$ ). Tra cứu trên cơ sở dữ liệu ngân hàng gen ty thể Mitomap chúng tôi chưa thấy có công bố nào liên quan đến hai biến đổi $\mathrm{T} 12150 \mathrm{G}$ và $\mathrm{C} 12154 \mathrm{G}$. Vì vậy, đây là những biến đổi mới được phát hiện ở bệnh nhân UTĐTT người Việt Nam.

Sử dụng chương trình RNAfold Server trong The Vienna RNA Websuite [7] để dự đoán cấu trúc bậc hai của phân tử tRNA ${ }^{\text {His }}$, kết quả dự đoán cho thấy biến đổi T12150G không dẫn đến thay đổi cấu trúc bậc 2 của phân tử tRNA $^{\text {His }}$ (Hình 3B). Trong khi đó, biến đổi C12154G làm thay đổi cấu trúc bậc hai của phân tử (Hình 3C), đặc biệt khi xảy ra đồng thời cả hai biến đổi T12150G và $\mathrm{C} 12154 \mathrm{G}$ (Hình 3D). Phần mềm đã cho phép xác định sự thay đồi năng lượng tự do tối thiểu (minimum free energy - MFE) của phân tử tRNA khi có biến đổi. Cụ thể, biến đổi của tRNA ${ }^{\text {His }}$ dẫn đến làm tăng năng lượng tự do tối thiểu từ $-10,4$ $\mathrm{kcal} / \mathrm{mol}$ (dạng không biến đổi) lên $-8,9$ $\mathrm{kcal} / \mathrm{mol}$ (khi có biến đổi $\mathrm{C} 12154 \mathrm{G}$ ) và $-9,3$ $\mathrm{kcal} / \mathrm{mol}$ (khi có đồng thời hai biến đổi T12150G và $\mathrm{C} 12154 \mathrm{G})$. Sự thay đổi về cấu trúc và sự tăng năng lượng tự do tối thiểu của tRNA có thể dẫn đến giảm độ bền của phân tử nên có thể ảnh hưởng đến chức năng của phân tử tRNA.

Đột biến gen mt-RNA đang ngày càng được công nhận là nhân tố quan trọng liên quan đến sự phát sinh một số bệnh trong đó có ung thư $[10,11]$. Các đột biến điểm trên tRNA có thể dẫn đến khiếm khuyết trong quá trình phiên mã, dịch mã, rối loạn chức năng chuỗi hô hấp ty thể và từ đó có thể liên quan đển đặc điểm lâm sàng của một số bệnh. Ở ung thư phổi, Wang và cs đã chỉ ra một số biến đổi trên gen tRNA có thể dẫn đến thay đổi cấu trúc của tRNA, do đó có thể làm giảm hiệu quả của sự nhận biết giữa codon - anticodon và quá trình mã hóa axit amin, điều đó có thể dẫn đến lượng ATP sản xuất dưới ngưỡng yêu cầu cho chức năng tế bào bình thường và góp phần phát sinh ung thư. Cụ thể, đột biến $\mathrm{A} 12172 \mathrm{G}$ làm thay đổi cẩu trúc và năng lượng tự do tối thiểu của tRNA ${ }^{\text {His }}$ và được xác định có vai trò quan trọng đối với ung thư phổi [6]. Trong nghiên cứu này chúng tôi đã sàng lọc thấy biến đổi $\mathrm{C} 12154 \mathrm{G}$ và $\mathrm{T} 12150 \mathrm{G}$ của $\mathrm{tRNA}^{\mathrm{His}}$ ở bệnh nhân UTĐTT và bằng phương pháp mô hình hóa cấu trúc bậc hai của RNA cũng nhận thấy biến đổi $\mathrm{C} 12154 \mathrm{G}$ làm thay đổi cấu trúc bậc hai và tăng năng lượng tự do tối thiểu của phân tử tRNA ${ }^{\text {His }}$, đặc biệt nếu có sự tồn tại đồng thời của hai biến đổi C12154G và $T 12150 \mathrm{G}$ (Hình $3 \mathrm{C}$ và $3 \mathrm{D})$. Trong cấu trúc của tRNA, đột biến gây bệnh thường xảy ra tại vùng gốc sau đến vùng DHU [12], vì vậy, biến đổi $\mathrm{C} 12154 \mathrm{G}$ thuộc vòng $\mathrm{DHU}$ làm thay đổi cấu trúc của $t R N A^{\text {His }}$ có thể ảnh hưởng đến chức năng của tRNA ${ }^{\text {His }}$ và từ đó có thể liên quan đến sự phát sinh UTĐTT.

Hơn nữa, trong mỗi tế bào, số lượng bản sao $\mathrm{ADN}$ ty thể dao động từ hàng trăm đến hàng nghìn bản sao. Các bản sao có thể giống nhau (dạng đồng tế bào chất, homoplasmy) hay không giống nhau (dị tế bào chất, heteroplasmy). Đa số các đột biến ADN ty thể tồn tại ở dạng dị tế bào chất $[6,9,13,14]$. Tương đồng với các kết quả nghiên cứu trên, trong nghiên này chúng tôi cũng đã xác định thấy các biến đổi A12309G, A12310G, T12150G 
và C12154G ở bệnh nhân UTĐTT đều tồn tại ở trạng thái dị tế bào chất. Tuy nhiên, ảnh hưởng của biến đổi đến biểu hiện lâm sàng của bệnh còn phụ thuộc vào mức độ dị tế bào chất của biến đổi. Vì vậy, việc nghiên cứu định lượng được mức độ dị tế bào chất của các biến đổi kể trên là cần thiết trong các nghiên cứu tiếp theo.

Đặc biệt, cả bốn biến đổi A12309G, A12310G, T12150G và C12154G được xác định trong nghiên cứu này đều là các biến đổi chưa từng được công bố trong các nghiên cứu trước đây trên đối tượng bệnh nhân ung thư. Vì vậy, đây có thể là những biến đổi mới của gen mt-tRNA ở đối tượng UTĐTT mà chúng tôi đã xác định được.

\section{Kết luận}

Bằng kỹ thuật PCR-RFLP và giải trình tự ADN, các biến đổi A12309G, A12310G thuộc gen tRNA ${ }^{\text {Leu }}, \mathrm{C} 12154 \mathrm{G}$ và $\mathrm{T} 12150 \mathrm{G}$ thuộc gen tRNA ${ }^{\text {His }}$ đã được xác định ở mẫu mô UTĐTT với tần suất tương ứng là $2,04 \%$ (với biến đổi A12309G, A12310G) và 5,26\% (với biến đổi C12154G và T12150G). Cả bốn biến đổi nêu trên đều ở trang thái dị tế bào chất và là các biến đổi mới chưa từng được công bố trên đối tượng bệnh nhân ung thư. Đặc biệt, bằng phương pháp mô hình hóa phân tử RNA bước đầu nhận thấy biến đổi $\mathrm{C} 12154 \mathrm{G}$ thuộc vùng DHU của tRNA ${ }^{\text {His }}$ làm thay đổi cấu trúc bậc hai của tRNA ${ }^{\text {His }}$ và làm tăng năng lượng tự do tối thiểu của phân tử, vì vậy biến đổi này có thể sẽ ảnh hưởng đến chức năng của tRNA ${ }^{\text {His }}$ và từ đó có thể góp phần vào sự phát sinh UTĐTT. Tuy nhiên, để đánh giá mối liên quan giữa các biến đổi nêu trên với các đặc điểm bệnh học của UTĐTT cũng như mối liên quan giữa mức độ đột biến với mức độ biểu hiện của bệnh thì việc tăng cỡ mẫu nghiên cứu và định lượng mức độ dị tế bào chất của các biến đổi là cần thiết.

\section{Lời cảm ơn}

Công trình được hoàn thành với sự hỗ trợ kinh phí của Đề tài cấp nhà nước KC.04.10/1115. Quy trình và các thủ tục lấy mẫu nghiên cứu được sự giúp đỡ từ các bác sỹ, y tá của Bệnh viện $\mathrm{K}$ - Hà Nội. Bệnh nhân tham gia nghiên cứu tự nguyện.

\section{Tài liệu tham khảo}

[1] International Agency for Research on Cancer. https://gco.iarc.fr/today/fact-sheets-cancers Colorectal cancer (accessed 30 November 2018).

[2] M. Brandon, P. Baldi, D.C Wallace, Mitochodrial mutations in cancer, Oncogene 25(34) (2006) 4647 4662. http://doi.org/ 10.1038/sj.onc.1209607.

G. Li, Y.X. Duan, X.B. Zhang, F. Wu, Mitochondrial RNA mutations may be infrequent in hepatocellular carcinoma patients, Genet. Mol. Res. 15(2) (2016) 1-7. http://doi.org/ 10.4238/ gmr.15027665.

[4] F. Mohammed, A.R. Rezaee, E. Mosaieby, M. Houshmand, Mitochondrial A12308G alteration in RNA Leu (CUN) in colorectal cancer samples, Diagn. Pathol. (2015) 10-115. http://doi.org/10. 1186/s13000-015-0337-6.

[5] S. Datta, M. Majumder, N.K. Biswas, N. Sikdar, B. Roy, Increased risk of oral cancer in relation to common Indian mitochondrial polymorphisms and Autosomal GSTP1 locus, Cancer. 110 (2007) 1991-1999. http://doi.org/ 10.1002/cncr.23016.

[6] L. Wang, Z.J. Chen , Y.K. Zhang, H.B. Le, The role of mitochondrial RNA mutations in lung cancer, Int. J. Clin. Exp. Med. 8 (8) (2015) 1-7. http://doi.org/ 10.3389/fgene.2014.00158.

[7] A.R. Gruber, R. Lorenz, S.H. Bernhart, R. Neubock, I.L Hofacker, The Vienna ARN Websuite, Nucleic Acids Res. 36 (2008) 70-74. http: /doi.org/10.1093/ nar/gkn188.

[8] Basic Local Alignment Search Tool. https://blast. ncbi.nlm.nih.gov/Blast.cgi/ nucleotide Blast (accessed 11 November 2018).

[9] Y. Goto, I. Nonaka, S. Horai, A mutation in the RNALeu (UUR) gene associated with the MELAS subgroup of mitochondrial encephalomyopathies, Nature 348 (6302) (1990) 651-653. http://doi.org/ $10.1038 / 348651 \mathrm{a} 0$.

[10] A human mitochondrial genome database. http://www.mitomap.org/MITOMAP (accessed 11 November 2018).

[11] A. Lorenc, J.B. Golik P, Homoplasmic MELAS A3243G mtDNA mutation in a colon cancer sample, Mitochondrion 3 (2) (2003) 119-124. https://doi.org/ 10.1016/S1567-7249(03)00106-5. 
[12] E.L. Blakely, J.W. Yarham, C.L. Alston, K. Craig, J. Poulton, C. Brierley, S.M. Park, A. Compston, C. Allen, S. Sharif , P. Enevoldso, M. Wilson, D.M. Turnbull, R.M. cFarland, R.W.Taylor, Pathogenic mitochondrial tRNA point mutations: nine novel mutations affirm their importance as a cause of mitochondrial disease, Hum. Mutat. 34 (9) (2013) 1260- 2068. https://doi.org/10.1002.
[13] S. DiMauro, Mitochondrial ADN medicine, Biosci. Rep. 27 (3) (2007) 5-9. https://doi.org $10.1007 /$ s 10540 -007-9032-5.

[14] D.C. Wallace, D. Chalkia, Mitochondrial ADN genetics and the heteroplasmy conundrum in evolution and disease, Cold Spring Harb Perspect Biol. 5 (11) (2013) 1-7. https://doi.org 10.1101/cshperspect. a021220. 